\title{
Distribution of Baseline Sensitivities to Natural Product Physcion Among Isolates of Sphaerotheca fuliginea and Pseudoperonospora cubensis
}

\author{
X. J. Yang, Agronomy and Biotechnology College, China Agricultural University, Beijing 10094, P.R. China, and \\ Institute for Plant Protection and Soil Sciences, Hubei Academy of Agricultural Sciences, Wuhan 430064, P.R. \\ China; L. J. Yang, F. S. Zeng, L. B. Xiang, S. N. Wang, and D. Z. Yu, Institute for Plant Protection and Soil Sci- \\ ences, Hubei Academy of Agricultural Sciences; and H. Ni, Agronomy and Biotechnology College, China Agricul- \\ tural University
}

\begin{abstract}
Yang, X. J., Yang, L. J., Zeng, F. S., Xiang, L. B., Wang, S. N., Yu, D. Z., and Ni, H. 2008. Distribution of baseline sensitivities to natural product physcion among isolates of Sphaerotheca fuliginea and Pseudoperonospora cubensis. Plant Dis. 92:1451-1455.

The ethanol extract from rhubarb was commercialized in China (Veguard, Physcion, $5 \mathrm{~g} /$ liter AS) for control of cucumber powdery mildew (Sphaerotheca fuliginea) and cucumber downy mildew (Pseudoperonospora cubensis). To provide the basic data for the risk assessment of resistance to this product, physcion was selected to represent the active ingredients to establish baseline sensitivity of powdery mildew and downy mildew populations. For powdery mildew, 262 isolates of $S$. fuliginea from nine regions and, for downy mildew populations, 116 isolates of P. cubensis from six regions were collected in China during 2004 and 2005 and tested for sensitivity. In addition, the sensitivity of a powdery mildew isolate was monitored for 15 asexual generations under selection pressure with physcion. The results showed that there was no significant difference among regions in the frequency distribution of baseline sensitivity to this ingredient for either cucumber powdery mildew isolates or cucumber downy mildew isolates. Baseline sensitivity was distributed as a normal unimodal curve with a mean median $(50 \%)$ effective concentration $\left(\mathrm{EC}_{50}\right)$ of $0.304 \mu \mathrm{g} / \mathrm{ml}$ for powdery mildew population and mean $\mathrm{EC}_{50}$ of $0.501 \mu \mathrm{g} / \mathrm{ml}$ for downy mildew population. The variation of sensitivity to physcion was low because the range factor (maximum $\mathrm{EC}_{50} /$ minimum $\mathrm{EC}_{50}$ of isolates within population) varied from 1.63 to 3.42 among powdery mildew populations and from 1.70 to 2.38 among downy mildew populations. The powdery mildew isolate XZ4 did not decrease sensitivity under the selection pressure of physcion at the dose of $\mathrm{EC}_{70}$ for 15 generations.
\end{abstract}

Both powdery mildew, caused by Sphaerotheca fuliginea (Schltdl.) Pollacci, and downy mildew, caused by Pseudoperonospora cubensis (Berk. \& M.A. Curtis) Rostovzev, are widespread diseases of greenhouse and field-grown cucumber plants and can lead to significant yield loss $(27,28)$. Despite efforts of plant breeders to develop resistant cultivars, it is not anticipated that genetic resistance will eliminate the need for fungicides (24). However, application of synthetic fungicides for plant disease control has resulted in environmental pollution, phytotoxicity to the host, and resistance of plant pathogens to fungicides $(13,23,29)$.

To reduce reliance on synthetic fungicides, one alternative measure may be the use of fungicidal plant extracts $(7,8,18)$. In addition to their bioactivity against a range of plant pathogens, plant extracts are biodegradable to nontoxic products and po-

Corresponding author: $\mathrm{H}$. Ni

E-mail: hanwenni@gmail.com

Accepted for publication 27 June 2008.

doi:10.1094/PDIS-92-10-1451

(C) 2008 The American Phytopathological Society tentially suitable for use in integrated management programs, and could lead to the development of a new class of disease control agents (2). The extract from leaves of the giant knotweed (Reynoutria sachalinensi (F. Schmidit) Nakai), containing anthraquinone physcion and so on, was commercialized as a wettable powder by Compo GmbH (Münster, Germany) in 1990. This product protects greenhousegrown cucumber, tomato, and begonia from powdery mildew $(8,12,19,20)$ and is also effective against Botrytis cinerea Pers. ex Fr. as well as Tobacco mosaic virus (9).

The ethanol-based extracts from the root of rhubarb (including Rheum officinale Baill, $R$. palmatum L., $R$. tanguticum Maxim Regel, R. emodi Wall., R. crispus L., $R$. laciniatum Prain, and others) have been shown to protect cucumber, wheat, and barley from powdery mildew fungi in greenhouse and field conditions $(7,30,35-$ $37)$. The extracts of rhubarb are also effective against a number of other plant pathogens, such as potato late blight (Phytophthora infestans (Mont.) de Bary) (15), tomato gray mold ( $B$. cinerea), wheat leaf rust (Puccinia recondita $\mathrm{f}$. sp. tritici), rice blast (Magnaporthe grisea (T.T. Hebert) M.E. Barr) (7), strawberry root rot (Rhizoctonia solani Kühn) (14), pepper mosaic disease, and tomato mosaic disease (10,38).

Many studies have isolated anthraquinones from the roots of Rheum emodi, the seed of Cassia tora L., and the leaves of $R$. sachalinensis by bioassaydirected fractionation and demonstrated them to be active against a range of plant pathogens with potential to control plant diseases $(7,12,18,19,36)$. The anthraquinones, including physcion, emodin, chrysophanol, and rhein, can be extracted using chromatography or by alkali-based methods $(5,7,18,25)$.

Genetic resistance of plant pathogens to fungicides is a severe problem with many of the site-specific fungicides used to control crop diseases. For example, the newly developed strobilurin fungicides are used to control pathogens resistant to fungicides such as ergosterol biosynthesis inhibitors and demethylation inhibitors (22). However, the resistance to strobilurin fungicides emerged soon after they were introduced $(3,13,22)$. The establishment of baseline sensitivity of a target plant pathogen to a new fungicide class is essential to assess the risk of fungicide resistance (16).

The ethanol plant extracts from the roots of rhubarb was commercialized for control of cucumber powdery and downy mildew (Veguard, Physcion, 5 g/liter AS; Beijing Kingbo Biotech. Co. Ltd., P.R. China) in 2007. The product contains physcion and other anthraquinone analogs, including chrysophanol, emodin, rhein, and so on. The activity of physcion against wheat powdery mildew was higher than that of other anthraquinones, and there is synergistic interaction between physcion and chrysophanol against powdery mildew pathogens $(34,35)$. Based on its commercial potential, this compound was selected to quantify the baseline sensitivity of powdery and downy mildew populations during 2004 and 2005. A second objective was to test the likelihood of fungicide resistance by measuring the change in sensitivity of one isolate of $S$. fuliginea under selection pressure of physcion under laboratory conditions.

\section{MATERIALS AND METHODS}

Compounds used. Physcion (98\%) (Fig. 1) was isolated using a modification of Chen's method (5). Ground rhizomes of 
$R$. officinale, purchased from the Beijing Tongrentang Co. Ltd. (Beijing) were refluxed with a solution of $20 \%$ aqueous $\mathrm{H}_{2} \mathrm{SO}_{4}+$ chloroform $(1+5$ by volume $)$ in a water bath for $3 \mathrm{~h}$. The chloroform phase was extracted with $0.25 \%$ aqueous potassium hydroxide; then, the organic solvent layer was extracted with $5 \%$ aqueous potassium hydroxide. This second aqueous fraction was acidified with hydrochloric acid to yield a yellow precipitate. The precipitate was filtered, washed with distilled water, and dried, yielding a mixture of chrysophanol and physcion. The physcion was then isolated and purified using column chromatography and identified by mass spectroscopy analysis (17). The compound was dissolved in acetone (10 $\mathrm{mg}$ per $10 \mathrm{ml}$ ) as stock solution and stored at $4^{\circ} \mathrm{C}$ in the dark before application.

Sample collection and isolate maintenance. During the cucumber growing season, leaves infected by powdery mildew or downy mildew were sampled from locations in nine regions, including Beijing, Wuchang, Zhengzhou, Nanjing, Tianjing, Xiaogan, Chengdu, Jingzhou, and Changsha in China during 2004 and 2005. The infected leaves were sampled from greenhouses or fields where physcion had never been applied. Leaves were kept in individual plastic bags with wet cotton covering the leafstalk for transport to the laboratory.

The powdery mildew samples were held in a chamber at $25 \pm 1{ }^{\circ} \mathrm{C}$ with fluorescent light at 12 -h intervals for 2 days to induce conidial production. Conidia from a single colony were transferred to healthy cucum- ber cotyledons with sterilized cotton swabs. The inoculated cotyledons were placed in covered petri dishes containing $2 \%$ water agar and kept in the chamber for propagation.

The downy mildew samples were placed in a humid chamber at $18 \pm 1^{\circ} \mathrm{C}$ overnight in darkness to induce sporulation. The zoosporangia of Pseudoperonospora cubensis were collected from a single lesion and rinsed with sterilized distilled water using a pipette. A zoosporangial suspension was inoculated onto the underside of a detached, healthy cucumber leaf. The inoculated leaves were transferred to covered petri dishes containing $2 \%$ water agar and then kept in the humid chamber for propagation.

Inoculum preparation. Seven days following inoculation with powdery mildew, conidia suspensions (about $2 \times 10^{5}$ spores/ml of distilled water, quantified by a hemacytometer) of each isolate of $S$. fuliginea were prepared by rinsing the infected leaves with sterilized distilled water containing Tween $80 \quad(0.025 \%$, $\mathrm{vol} / \mathrm{vol}$ ) with a pipette; then, each conidia suspension was passed through two layers of glass paper. Likewise, the zoosporangia suspensions (about $2 \times 10^{4}$ zoosporan$\mathrm{gia} / \mathrm{ml}$ ) of candidate isolate of $P$. cubensis were prepared in the same way.

Baseline sensitivity assays. A series of physcion concentrations at 10.0, 2.5, 0.63, 0.15 , and $0.04 \mu \mathrm{g} / \mathrm{ml}$ were used for the cucumber powdery mildew assay and 12.5 , $3.125,0.78,0.19$, and $0.048 \mu \mathrm{g} / \mathrm{ml}$ for the cucumber downy mildew assay. Tween 80 was added in the final dilutions at the rate

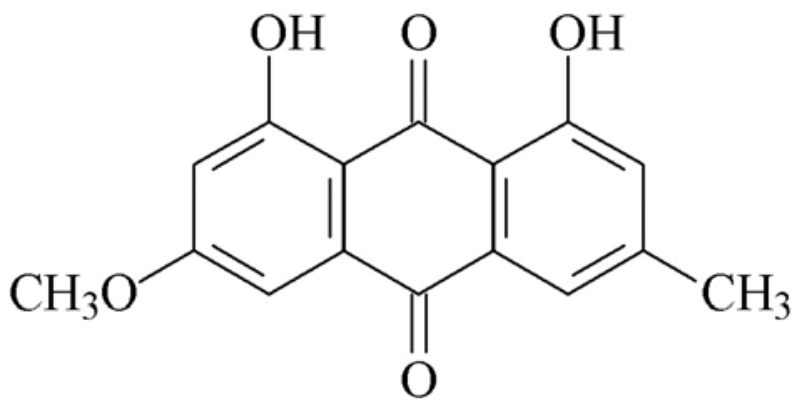

Fig. 1. Chemical structure of physcion tested.

of $0.025 \%(\mathrm{vol} / \mathrm{vol})$. Based on the preliminary experiments, there was no difference between untreated control and negative control in disease severity. Therefore, only the negative control was utilized for data analysis.

For the powdery mildew assay, physcion was sprayed on cucumber plants at the cotyledon stage using an autosprayer tower with 0.25 MPa (Model PWT-510, manufactured by the Pesticide Machinery Group of the China Agricultural University). Spray volume was $25 \mathrm{ml} / \mathrm{m}^{2}$. After air drying, the cotyledons were detached and put into petri dishes (60 $\mathrm{mm}$ in diameter) containing water agar $(2 \%)$ with three cotyledons in each dish. Then the treated cotyledons were inoculated by uniformly misting leaf surfaces with conidia suspensions. After inoculation, the petri dishes were air dried to remove water drops on the leaves and then incubated in a chamber at $25 \pm 1^{\circ} \mathrm{C}$ without light for $16 \mathrm{~h}$. Spores on the surface of cotyledons were sampled with transparent tape and then the tape was placed on a slide. After adding $0.1 \mathrm{ml}$ of aqueous lactic acid and glycerin (lactic acid/glycerin/water = $1 / 2 / 1, \mathrm{vol} / \mathrm{vol} / \mathrm{vol}$ ), the total conidia and germinated conidia were counted with a microscope at $\times 100$ magnification. Germination inhibition rates (IR) were calculated as follows: IR $(\%)=[($ GR untreated - GR treated)/GR untreated] $\times 100$, where GR indicates germination rate.

For downy mildew assay, a leaf disc assay was used. Cucumber leaf discs $(15 \mathrm{~mm}$ in diameter) from the fourth true leaves at the five-leaf stage were submerged in corresponding physcion solutions for $5 \mathrm{~s}$ and put into petri dishes $(90 \mathrm{~mm}$ in diameter) with water agar (2\%). Each petri dish had 18 leaf discs. After air drying, a zoosporangia suspension of $10 \mu \mathrm{l}$ was inoculated on each leaf disc with a pipette. The petri dishes were covered and placed in a humid chamber at $18 \pm 1^{\circ} \mathrm{C}$ in darkness overnight, then moved into a growth chamber with $18 \pm 1^{\circ} \mathrm{C}$ and fluorescent light at 12 -h intervals for disease development. Disease severities were scored 7 days after inoculation by visually assessing the percentages of leaf areas infected, and converted to \% disease control according to Abbott's

Table 1. Sensitivity to natural product physcion of Sphaerotheca fuliginea isolates collected from nine regions in China during 2004 and 2005

\begin{tabular}{|c|c|c|c|c|c|c|}
\hline \multirow[b]{2}{*}{ Region } & \multirow[b]{2}{*}{ No. of isolates tested } & \multicolumn{3}{|c|}{$\mathrm{EC}_{50}(\mu \mathrm{g} / \mathrm{ml})^{\mathrm{a}}$} & \multirow[b]{2}{*}{$\mathbf{R F}^{\mathbf{b}}$} & \multirow[b]{2}{*}{ Mean $\operatorname{rank}(P=0.50)^{\mathrm{c}}$} \\
\hline & & Median & Minimum & Maximum & & \\
\hline Beijing & 19 & 0.302 & 0.175 & 0.406 & 2.32 & 150.0 \\
\hline Wuchang & 57 & 0.299 & 0.265 & 0.454 & 1.71 & 126.0 \\
\hline Jingzhou & 55 & 0.282 & 0.204 & 0.446 & 2.19 & 117.8 \\
\hline Tianjing & 11 & 0.281 & 0.232 & 0.379 & 1.63 & 122.3 \\
\hline Nanjing & 15 & 0.310 & 0.253 & 0.433 & 1.71 & 152.8 \\
\hline Xiaogan & 29 & 0.297 & 0.153 & 0.447 & 3.42 & 140.8 \\
\hline Chengdu & 29 & 0.293 & 0.199 & 0.417 & 2.10 & 121.6 \\
\hline Zhengzhou & 31 & 0.295 & 0.166 & 0.400 & 2.41 & 135.4 \\
\hline Changsha & 16 & 0.312 & 0.217 & 0.364 & 1.68 & 156.3 \\
\hline
\end{tabular}

${ }^{\mathrm{a}} \mathrm{EC}_{50}=$ mean $50 \%$ effective concentration.

${ }^{\mathrm{b}}$ Range factor $(\mathrm{RF})=$ maximum $\mathrm{EC}_{50} /$ minimum $\mathrm{EC}_{50}$ of isolates within population.

${ }^{\mathrm{c}}$ Indicates that the medians among regions are not significantly different using the Kruskal-Wallis nonparametric test. 
method (1): percent disease control $=100$ $\times[($ untreated - treated $) /$ untreated $]$.

The median $(50 \%)$ effective concentration $\left(\mathrm{EC}_{50}\right)$ for each isolate was calculated using simple linear regression of the Probit-transformed percentage of germination inhibition (for powdery mildew) or percentage of disease control (for downy mildew) against the $\log$ of physcion concentration. For the isolates of each region over year, curve shape was determined using the Kolmogorov-Smirnov test. The differences of mean ranks were determined using the Kruskal-Wallis nonparametric test. The baseline sensitivity was calculated over region and year because there were no differences either among regions or between years based on the Kruskal-Wallis nonparametric test. All analyses of data were done by SSPS 10.0.

Sensitivity monitoring of $S$. fuliginea isolate under selection pressure of physcion. Single-colony isolate XZ4 of $S$. fuliginea, with an $\mathrm{EC}_{50}$ value close to the sensitivity baseline, was used as the initial generation (G0). The isolate was inoculated onto cucumber cotyledons treated with physcion using a dose of $0.829 \mu \mathrm{g} / \mathrm{ml}$ (about $\mathrm{EC}_{70}$ based on preliminary experiments). The surviving conidia were used as the first generation (G1) to inoculate cotyledons treated with physcion at the same dose to obtain the second generation (G2). This selection was repeated for 15 generations (G15). For each generation, $\mathrm{EC}_{50}$ values were assessed as in the above method.

The $\mathrm{EC}_{50}$ value of G1 to G15 was compared with that of G0 by $t$ test, and a correlation analysis was conducted to determine if the $\mathrm{EC}_{50}$ value changed across generations under constant selection pressure of physcion.

\section{RESULTS}

Baseline sensitivity of cucumber powdery mildew isolates. The median, maximum, and minimum $\mathrm{EC}_{50}$; population size; range factor; and mean rank of powdery mildew population from each sampling region over year are listed in Table 1. The Kruskal-Wallis nonparametric test showed that there were no significant differences in the mean rank and the distribution of baseline sensitivity among nine regions $(P$ $=0.505, P>0.05)$. The distribution given by the 262 isolates was a normal unimodal curve by Kolmogorov-Smirnov nonparametric test $(P=0.513, P>0.05)$. The $\mathrm{EC}_{50}$ values ranged from 0.153 to $0.454 \mu \mathrm{g} / \mathrm{ml}$ with a mean value $0.304 \pm 0.006 \mu \mathrm{g} / \mathrm{ml}$ (Fig. 2). The sensitivity range factors of populations from nine regions varied from 1.63 to 3.42 (Table 1 ). These results indi-

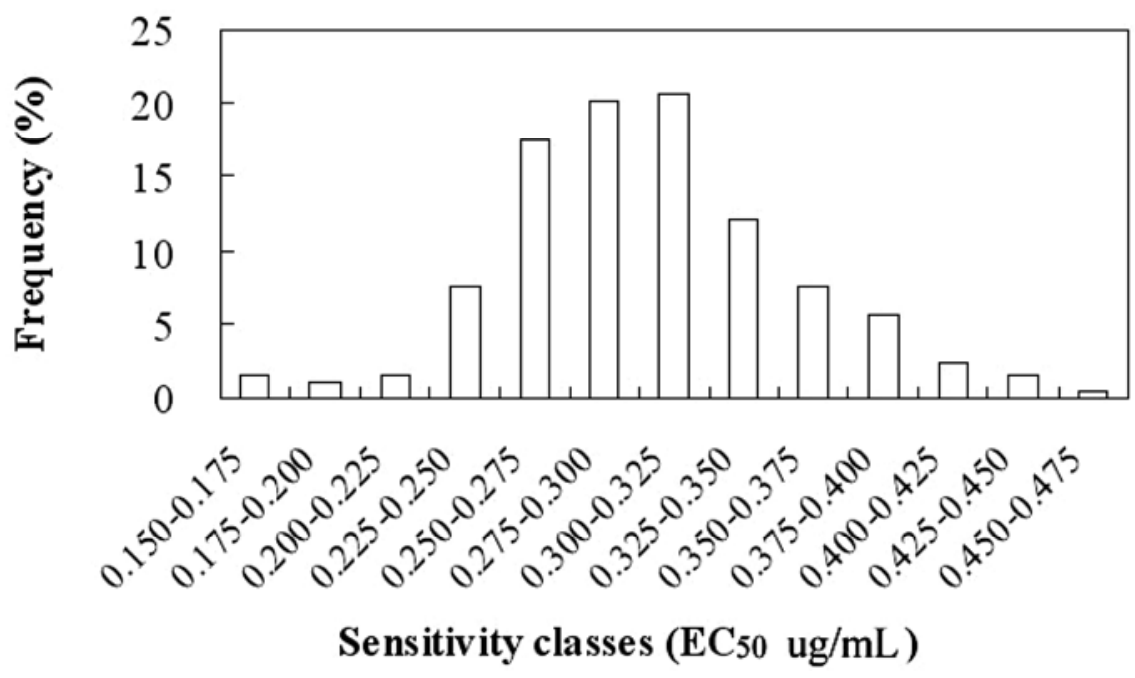

Fig. 2. Baseline sensitivity of Sphaerotheca fuliginea isolates (262 isolates from 2004 and 2005) to physcion collected from nine regions in China. Mean median $(50 \%)$ effective concentration $\left(\mathrm{EC}_{50}\right)$ value $=0.304 \pm 0.006 \mu \mathrm{g} / \mathrm{ml}$. cate that there was no resistant subpopulation among the isolates of cucumber powdery mildew used in this study.

Baseline sensitivity of cucumber downy mildew isolates. Similar results were obtained using a cucumber downy mildew population. The Kruskal-Wallis nonparametric test showed that there were no significant differences in mean rank and sensitivity distribution among 6 regions $(P$ $=0.367, P>0.05$ ) (Table 2). The distribution of the 116 isolates also was a normal unimodal curve $(P=0.596, P>0.05)$ and the baseline sensitivity ranged from 0.280 to $0.748 \mu \mathrm{g} / \mathrm{ml}$, with a mean value of 0.501 $\pm 0.017 \mu \mathrm{g} / \mathrm{ml}$ (Fig. 3). The sensitivity range factors from the six regions were from 1.70 to 2.38 (Table 2). The finding showed that no resistant subpopulation existed among the isolates of cucumber downy mildew used in the experiment.

Sensitivity monitoring of $S$. fuliginea isolate under selective pressure of physcion. The $\mathrm{EC}_{50}$ values $\mathrm{G} 1$ to $\mathrm{G} 15$ of $S$. fuliginea under the selection pressure of physcion ranged from 0.249 to 0.395 $\mu \mathrm{g} / \mathrm{ml}$. The $\mathrm{EC}_{50}$ value of the initial was $0.301 \mu \mathrm{g} / \mathrm{ml}$, and the $t$ test showed that the $\mathrm{EC}_{50}$ values of $\mathrm{G} 1$ to $\mathrm{G} 15$ were not significantly different from the $\mathrm{EC}_{50}$ of their initial isolate. $\mathrm{EC}_{50}$ values of $\mathrm{G} 0$ to $\mathrm{G} 15$ did not increase with increase in generation (Fig. 4). This finding indicated the sensitivity of $S$. fuliginea remained unchanged under the selection pressure of physcion for 15 generations.

\section{DISCUSSION}

In this study, we determined the baseline sensitivities of two cucumber pathogens to physcion, a novel, natural product isolated from rhubarb plants. Powdery mildew and downy mildew were studied and established a sensitivity baseline of $0.304 \pm$ $0.006 \mu \mathrm{g} / \mathrm{ml}$ for $S$. fuliginea and $0.501 \pm$ $0.017 \mu \mathrm{g} / \mathrm{ml}$ for $P$. cubensis. These baselines will be used to monitor any shift of sensitivity in cucumber powdery mildew and downy mildew populations to physcion.

The variations in the powdery mildew and downy mildew populations to physcion were relatively low. In the selection assay, it appeared that sensitivity of $S$. fuliginea was stable after 15 generations of continuous selection. In the case of stro-

Table 2. Sensitivity to natural product physcion of Pseudoperonospora cubensis isolates collected from six regions in China during 2004 and 2005

\begin{tabular}{|c|c|c|c|c|c|c|}
\hline \multirow[b]{2}{*}{ Region } & \multirow[b]{2}{*}{ No. of isolates tested } & \multicolumn{3}{|c|}{$\mathrm{EC}_{50}(\mu \mathrm{g} / \mathrm{ml})^{\mathrm{a}}$} & \multirow[b]{2}{*}{$\mathbf{R F}^{\mathbf{b}}$} & \multirow[b]{2}{*}{ Mean rank $(P=0.50)$} \\
\hline & & Median & Minimum & Maximum & & \\
\hline Beijing & 17 & 0.498 & 0.325 & 0.748 & 2.30 & 60.0 \\
\hline Wuchang & 32 & 0.443 & 0.280 & 0.667 & 2.38 & 49.4 \\
\hline Jingzhou & 14 & 0.521 & 0.418 & 0.709 & 1.70 & 67.6 \\
\hline Nanjing & 15 & 0.472 & 0.310 & 0.730 & 2.35 & 52.3 \\
\hline Xiaogan & 21 & 0.514 & 0.401 & 0.689 & 1.72 & 67.1 \\
\hline Zhengzhou & 17 & 0.502 & 0.360 & 0.710 & 1.97 & 61.5 \\
\hline
\end{tabular}

${ }^{\mathrm{a}} \mathrm{EC}_{50}=50 \%$ effective concentration.

${ }^{\mathrm{b}}$ Range factor $(\mathrm{RF})=$ maximum $\mathrm{EC}_{50} /$ minimum $\mathrm{EC}_{50}$ of isolates within population.

${ }^{\mathrm{c}}$ Indicates that the medians among regions is not significantly different using the Kruskal-Wallis nonparametric test. 
bilurin fungicides, changes in sensitivity could be found within one to three growing seasons (31), which is equal to approximately 5 to 15 generations of $S$. $f u$ liginea. Han et al. (11) reported that the range in the baseline sensitivity of cucumber downy mildew to azoxystrobin, one of the strobilurin fungicides, was 79.8 (minimum $11.7 \times 10^{-5} \mu \mathrm{g} / \mathrm{ml}$ and maximum $\left.9.34 \times 10^{-3} \mu \mathrm{g} / \mathrm{ml}\right)$. This indicates that the variation of sensitivity to this type of fungicide was very high in the pathogen population compared with our findings with physcion. Strobilurin fungicides are sitespecific inhibitors which act as inhibitors of electron transport from cytochrome $\mathrm{b}$ to $\mathrm{c} 1$ on the mitochondrial respiration system and, therefore, are considered to have a high potential resistance risk for resistance development in pathogen populations when they are used in agricultural settings (32).
Plant extracts of $R$. officinale have been used in traditional Chinese herbal medicine and are widely used in clinics to treat the hepatitis B virus $(26,33)$. Studies have shown that the mechanism of action of the anthraquinones, including emodin, rhein, aloe-emodin physcion, and chrysophanol, for treating the human pathogen Staphylococcus aureus was inhibition of protein synthesis (21). Studies have investigated activity against the carcinoma cells of Ehrlich ascites through inhibition of respiration, oxidation, and dehydrogenization of some amino acids and intermediate products of carbohydrates metabolism and glycolysis (6), and as inhibitors of some enzymes of the mitochondrial electron transport system (4). However, the action mechanism of anthraquinones against plant pathogens has not been determined.

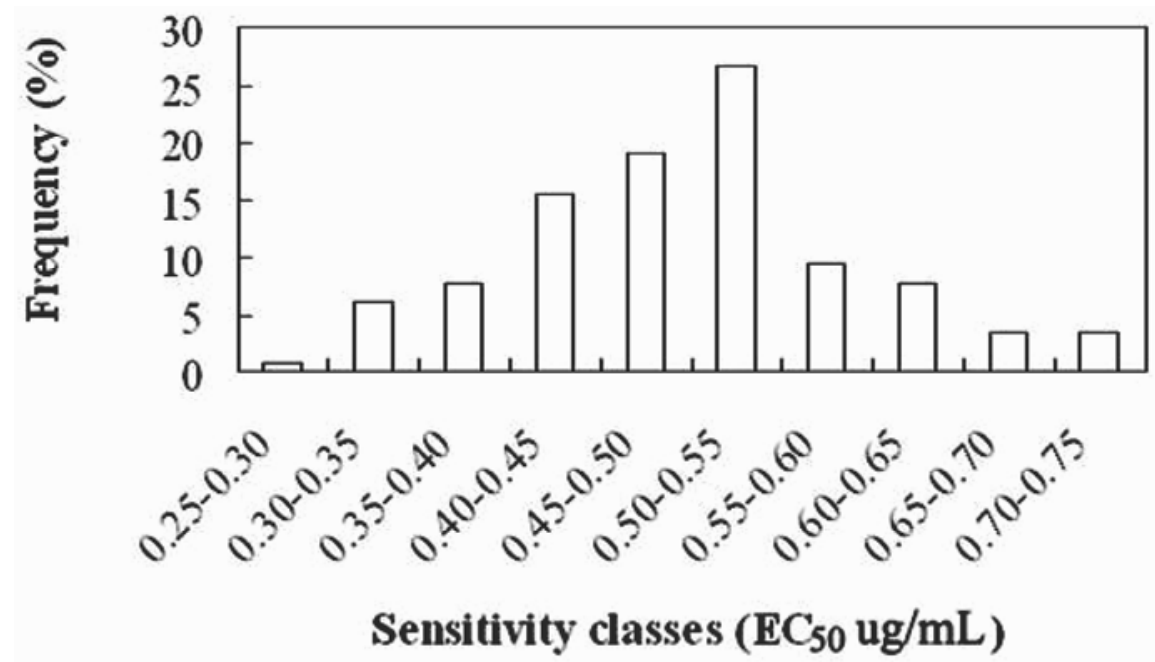

Fig. 3. Baseline sensitivity of Pseudoperonospora cubensis isolates (116 isolates from 2004 and 2005) to physcion collected from six regions in China. Mean median (50\%) effective concentration $\left(\mathrm{EC}_{50}\right)$ value $=0.501 \pm 0.017 \mu \mathrm{g} / \mathrm{ml}$.



Fig. 4. Sensitivity dynamics of Sphaerotheca fuliginea under the selection pressure of physcion. Median $(50 \%)$ effective concentration $\left(\mathrm{EC}_{50}\right)$ values of $S$. fuliginea to physcion ranged from 0.249 to $0.395 \mu \mathrm{g} / \mathrm{ml}$ and were not significantly different from the initial isolate XZ4 by $t$ test. The correlation analysis $\left(R^{2}=0.027\right)$ indicated the $\mathrm{EC}_{50}$ values did not increase with the increase of generation under the selection of the compound.
The results of this study show little variation in sensitivity among the populations of the two distinct plant pathogens to the fungicide physcion. Both plant pathogens have high reproduction rates and, as such, are at higher risk for resistance development. After 15 generations of exposure, there was no change in $\mathrm{EC}_{50}$. Based on this evidence, it is likely that physcion will have a low to moderate risk for resistance development.

\section{LITERATURE CITED}

1. Abbott, W. S. 1925. A method for computing the effectiveness of an insecticide. J. Econ. Entomol. 18:265-267.

2. Balandrin, M., Klocke, J., Wurtele, E. S., and Bollinger, W. H. 1985. Natural plant chemicals: Sources of industrial and medicinal materials. Science 228:1154-1160.

3. Beresford, R., Park, H., and Brown, G. 1999. Strategies to avoid resistance development to strobinlurin and related fungicides in New Zealand. Pages 179-182 in: Proc. 52nd N. Z. Plant Prot. Conf. New Zealand Plant Protection Society, eds. Rotorua, New Zealand.

4. Chen, C. L., and Chen, Q. H. 1987. Biochemical study of Chinese rhubarb. XIX. Localization of inhibition of anthraquinone derivatives on the mitochondrial respiratory chain. Acta Pharmacol. Sin. 22 (1):12-18.

5. Chen, Q. H., Dai, H. S., and Su, X. L. 2001. Studies on Chinese rhubarb-XXXI: Improved method for systematic isolation of anthraquinones from rhubarb. Nat. Prod. Res. Dev. 13 (3):58-60.

6. Chen, Q. H., Liu, C. R., and Qiu, C. H. 1980. Biochemical study of Chinese rhubarb. XII. Effect of antraquinone derivatives on the respiration and glycolysis of Ehrlich ascites carcinoma cell. Acta Pharmacol. Sin. 15(2):6570 .

7. Choi, G. J., Lee, S. W., Jang, K. S., Kim, J. S. Cho, K. Y., and Kim, J. C. 2004. Effects of chrysophenol, parietin, and nepodin of Rumex cripus on barley and cucumber powdery mildews. Crop Prot. 23:1215-1221.

8. Daayf, F., Schmitt, A. and Bélanger, R. R. 1995. The effects of plant extracts of Reynoutria on powdery mildew development and leaf physiology of long English cucumber. Plant Dis. 79:577-580.

9. Fritz, I. 1996. Physiologysche Wirkungen von Resistenzinduktoren: Primäre und sekundäre Reaktionen im Wirt-PathogenSystem Gurke/ Echter Gurkenmehltau. Ph.D. dissertation, Technische Hochschule, Darmstadt, Germany.

10. Guo, X. Q., Zhu, H. C., Yan, D. Y., Li, X. D., and Zhu, X. P. 1998. Control effects of the extract from Rheum palmatum L. on tomato mosaic disease caused by TMV. J. Shandong Agric. Univ. 29 (2):171-175.

11. Han, X. Y., Ma, Z. Q., Li, H. X., Kang, L. D., and Zhang, X. F. 2004. Study on the sensitive baseline of Pseudoperonospora cubensis to the fungicide azoxystrobin. Chin. J. Pestic. Sci. 6 (2):76-79.

12. Herger, G., and Klingauf, F. 1990. Control of powdery mildew fungi with extracts of the giant knotweed, Reynoutria sachalinensis (Polygonaceae). Meded. Fac. Landbouwwet. Rijksuniv. Gent 55:1007-1014.

13. Ishii, H., Fraaije, B. A., and Sugiyama, T. 2001. Occurrence and molecular characterization of strobinlurin resistance in cucumber powdery mildew and downy mildew. Phytopathology 91:1166-1171.

14. Jiang, J. Z., and Lian, N. 2005. Inhibition of plant extracts on growth of strawberry root rot fungi. J. Hebei Univ. Nat. Sci. Ed. 25 (4):399404. 
15. Jiang, J. Z., Zhao, L. K., Zhen, X. B., and Lu, J. Y. 2001. Resistance to Phytophthora infestans in potato induced with plant extracts. Acta Phytopathol. Sin. 31 (2):144-151.

16. Justum, A. R., Heaney, S. P., Perrin, B. M., and Wege, P. J. 1998. Pesticide resistance: assessment of risk and implementation of effective management strategies. Pestic. Sci. 54:435436.

17. Kalidhar, S. B. 1989. Location of glycosylation and alkylation sites in anthraquinones by ${ }^{1} \mathrm{H}$ NMR. Phytochemistry 28 (9):2455-2458.

18. Kim, Y. M., Lee, C. H., Kim, H. G., and Lee, H. S. 2004. Anthraquinones isolated from Cassia tora (Leguminosae) seed show an antifungal property against phytopathogenic fungi. J. Agric. Food Chem. 52:6096-6100.

19. Konstantinidou-Doltsinis, S., Markellou, E., Kasselaki, A. M., Fanpouaki, M. N., Koumaki, C. M., Schmitt, A., Liopa-Tsakalidis, A., and Malathrakis, N. E. 2006. Efficacy of Milsana, a formulated plant extract from Reynoutria sachalinensis, against powdery mildew of tomato (Leveillula taurica). BioControl 51 (3):375-392.

20. Konstantinidou-Doltsinis, S., and Schmitt, A. 1998. Impact of treatment with plant extracts from Reynoutria sachalinensis (F. Schmidit) Nakai on intensity of powdery mildew severity and yield in cucumber under high disease pressure. Crop Prot. 17 (8):649-656.

21. Li, D. D., Su, H. L., and Chen, Q. H. 1964. Studies of Chinese rhubarb. VIII. Mechanism of anthraquinone derivatives. (2) Effect on the metabolism of nitrogen containing compound in Staphylococcus aureus. Acta Biochem. Biophys. Sin. 4(2):151-160.

22. Margot, P., Huggenberger, F., and Amrein, J.
1998. A new broad-spectrum stobinlurin fungicid. Pages 375-382 in: Brighton Crop Prot. Conf. Pests Dis. British Crop Protection Counci1, eds. Farnham, UK.

23. McGrath, M. T. 1996. Increased resistance to triadimefon and to benomyl in Sphaerotheca fuliginea populations following fungicide usage over one season. Plant Dis. 80 (6):633639.

24. McGrath, M. T., Staniszewska, H., and Shishkoff, N. 1996. Fungicide sensitivity of Sphaerotheca fuliginea populations in the United States. Plant Dis. 80 (6):697-703.

25. Min, D., Xu, L. P., and Zhang, Z. Z. 1998. Studies on ingredients of rhubarb (I). J. Chin. Trad. Med. 23 (7):417.

26. Qian, Y. X., Jiao, D. H., and Ma, Y. H. 1986. Studies on clinic pharmacology of troche extracted from Rheum officinale Baill with ethanol. Chin. Trad. Herb. Drugs 17:411-412.

27. Reuveni, M., Agapov, V., and Reuveni, R. 1996. Controlling powdery mildew by Sphaerotheca fuliginea in cucumber by foliar spray of phosphate and potassium salts. Crop Prot. 15 (1):49-53.

28. Shi, Y. X., Li, B. J. and Liu, X. M. 2002. The study of cucumber downy mildew. J. Northeast Agric. Univ. 33 (4):391-395.

29. Sierotzki, H., Wullschleger, J., and Gisi, U. 2000. Point mutation in cytochrome b gene conferring resistance to strobilurin fungicides in Erysiphe graminis f. sp. tritici field isolates. Pestic. Biochem. Phys. 68:107-112.

30. Tang, R., Zhang, X. H., Hu, T. L., and Cao, K. Q. 2003. Control effects from Rheum palmatum on powdery mildew of cucumber. J. Anhui Agric. Univ. 30 (4):363-366

31. VonJagow, G., Gribble, G. W., and Trumpower,
B. L. 1986. Mucidin and strobilurin A are identical and inhibit electron transfer in the cytochrome bc-1 complex of the mitochondrial respiratory chain at the same site as myxothiazol. Biochemistry 25:775-780.

32. Wong, F. P., and Wilcox, W. F. 2002. Sensitivity to azoxystrobin among isolates of Uncinula necator: baseline distribution and relationship to myclobutanil sensitivity. Plant Dis. 86 (4):394-404.

33. Xu, Z. J., Huang, Y. Q., Yang, H., Li S. Q., and Wang, C. G. 2004. The Clinic observation of antivirus activity of Rheum officinale Baill on HBV. Fujian Med. J. 26 (3):69-70.

34. Yang, X. J. 2007. The bioactivity and action mechanism of natural anthraquinone compounds against fungal phytopathogens. Ph.D. dissertation, China Agricultural University, Beijing

35. Yang, X. J., Yang, L. J., Wang, S. N., Yu, D. Z and Ni, H. W. 2007. Synergistic interaction of physcion and chrysophanol on plant powdery mildew. Pest Manage. Sci. 63(5):511-515.

36. Yu, D. Z., Yang, X. J., Ni, H. W., Yang, L. J., Wang, S. N., and Zhao, Y. Y. 2006. Use of anthraquinone derivatives as pesticides to controlling plant disease. P. R. China Patent ZL 03 125346.6.

37. Yu, D. Z., Yang, L. J., Yang, X. J., Wang, S. N. and Zhang, H. Y. 2004. Bioactivity screening of crude extracts from plants to Blumeria graminnis. J. Hunan Agric. Univ. 30 (2):142 144.

38. Zhu, S. F., and Chiu, W. F. 1989. A primary study of the therapeutic effects of some medicinal herb-extracts on the pepper mosaic caused by CMV. Acta Phytopathol. Sin. 19 (2):123-128. 